\title{
BRANCHED POLYESTERS FROM GERMYLATED AND FATTY COMPOUNDS
}

\author{
NADIA KATIR I,4, DANIELA ANDRADE ${ }^{2}$ MOHAMED DAHROUCH ${ }^{2, *}$, ENZO DÍAZ2,

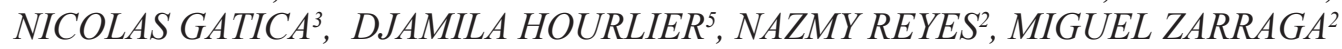 \\ ${ }^{1}$ Laboratoire d'Hétérochimie Fondamentale et Appliquée, UMR-CNRS 5069, Université Paul Sabatier, 118 Route de Narbonne, \\ 31062 Toulouse cedex 9, France. \\ ${ }^{2}$ Departamento de Química Orgánica, Facultad de Ciencias Químicas, Universidad de Concepción, Casilla 160-C, Concepción, Chile. E-mail adress: \\ mdahrouch@udec.cl, telephone: 56-412204258, fax numbers:56-412245974. \\ ${ }^{3}$ Departamento de Polimeros, Facultad de Ciencias Químicas, Universidad de Concepción, Casilla 160-C, Concepción, Chile. \\ ${ }^{4}($ iNANOTECH) Institute of Nanomaterials and Nanotechnology - MAScIR (Moroccan Foundation for Advanced Science, \\ Innovation and Research), ENSET, Avenue de l'Armée Royale, Madinat El Irfane, 10100 Rabat, Morocco. \\ 'Institut d'Electronique, de Microélectronique et de Nanotechnologie IEMN UMR 8520 Avenue Henri Poincare BP 60069 F-59652 Villeneuve d'Ascq Cedex
}

\section{ABSTRACT}

Here we report the synthesis of news branched polyesters derived from the trans-esterification reactions at moderate temperatures $\left(140-190^{\circ} \mathrm{C}\right)$, either from polyglycols with different molecular weights and monomers such as germylated fatty tri-esters, or from dimethyl terephtalate and germylated fatty tri-alcohol. The structure of the resulting polymers was determined by elemental analysis, FTIR, and ${ }^{13} \mathrm{C}$ CP MAS NMR, and their thermal properties by thermogravimetry analysis and differential scanning calorimetry. ${ }^{13} \mathrm{C} \mathrm{CP}$ MAS NMR analysis indicates that the characteristic signals due to the methoxy groups of the germylated fatty tri-ester and the $\mathrm{CH}_{2} \mathrm{OH}$ group of germylated fatty tri-alcohol completely disappeared. This suggests that the trans-esterification process reached a nearly complete conversion. All germylated branched polyesters are insoluble in classic organic solvents due to their polydimensional structure. Thermal properties of these new materials showed that they do not present any cristallinity phase, and undergo thermal decomposition above $300^{\circ} \mathrm{C}$.

Keywords: Polymer synthesis, thermal properties, branched biopolyesters, fatty compounds; germanium compounds.

\section{INTRODUCTION}

In the past few years there has been a great effort directed toward natural resources to produce the next generation of products and processes by attempting to apply a set of principles based on green chemistry and feedstocks that are renewable and less toxic to human health and to the environment ${ }^{1-4}$. For example, natural oils provide an attractive alternative to current synthetic polymers based exclusively on petroleum feedstocks ${ }^{5-10}$. Some of the more promising polymeric substances are those obtained from fatty acids, which are biocompatible, cost effective, and biodegradable ${ }^{5-12}$. The specific usefulness of fatty acids is determined by the presence of carbon-carbon double bonds and acid functions, susceptible to cationic, radical polymerizations or polyesterification reactions ${ }^{13-16}$. All these reactions open up new vistas to chemists. Thus, a wide choice of compounds is available; among them, there are organometallic polymers which contain inorganic elements $(\mathrm{Si} / \mathrm{Ge})$ as part of their main chain structure or as pendent group. French workers have made a significant contribution in the area of silylated and germylated fatty compounds 17-18. These compounds should represent a growing field of research as they offer a wide range of interesting properties and applications observed in many organometallic polymers ${ }^{16,19-28}$. The structural investigations indicate that silicon or germanium based-polymers can exist with various skeletal structures such as linear, branched or cross-linked polymers. Linear polymers are usually prepared from monomers which present two functional groups, whereas in the case of branched polymers, the monomer structures should exhibit at least three functional groups which, after polymerization, should produce a three-dimensional structure. Although branched polymers exhibit usually very low solubility in classical solvents, the interest in these kinds of materials is growing intensively because the macromolecular organization can allow the formation of interesting cavities needed for specific applications as in catalysis, as additives or as new film materials ${ }^{29-36}$.

Recently, we reported on the synthesis and characterization of fatty methyl di-ester (FAME) containing silicon and germanium elements via catalyzedhydrosilylation and hydrogermylation reactions ${ }^{16}$. The new class of metallated fatty methyl diesters was used as monomers in polymerization reactions of polytransesterification with poly(tetramethylene oxide) glycol of different molecular weights. Linear organometallic polyesters were obtained and characterized successfully. The physical study of these condensed materials showed that they are amphiphilic and they adopt a nano container structure, which could lead to very interesting applications in various fields of chemistry, especially in drug delivery and release of bio-active molecules ${ }^{16}$. These reactions can also be adapted to the synthesis of branched organometallic polyesters by varying either one or both of the monomers containing at least three functionalities. Katir et al ${ }^{17-18}$ have reported reactions of hydrogermylation of fatty acid methyl ester and fatty alcohol which produced germylated fatty tri-ester and tri-alcohol, respectively. The resulting products showed that in particular solvents, they can self-assemble into well-organized nano- and microstructure with potential applications in biosurfactants. This work continues our initial study concerning the use of fatty compounds in order to compare physical and thermal properties of disubstituted unit derivatives with the analogous trisubtituted compounds. Thus, germylated fatty tri-ester and tri-alcohol were used as monomers in polytransesterification reactions with poly(tetramethylene oxide) glycols of different molecular weights and dimethyl terephthalate. The structure of the organometallic polyesters is studied by spectroscopic techniques. The thermal behavior of the polyesters is usually a very important study for futures applications, and consequently a description of thermogravimetric analysis (TGA) and differential scanning calorimetry (DSC) of these materials is also reported.

\section{RESULTS AND DISCUSSION}

The polytransesterification takes place between germylated fatty tri-ester and diol monomers as 1,4-butandiol, Poly(tetramethylene oxide) glycol with a molecular weight $\mathrm{M}_{\mathrm{n}}$ of 650 and $1000 \mathrm{~g} / \mathrm{mol}$, to form oligomers by gradually heating the mixture to $140^{\circ} \mathrm{C}$ (Equation 1). The polytransesterification is catalyzed by tetrabutyl titanate. This last compound showed high catalytic efficiency in Lewis acid-catalyzed reactions. In order to shift the equilibrium and reach higher molecular weight, the reaction is carried out under vacuum $(0.5 \mathrm{mmHg})$ while increasing temperature to $190^{\circ} \mathrm{C}$ and allowing the total evaporation of methanol which has been isolated and identified. The process is considered to be complete after one supplementary hour under stirring, assuming $100 \%$ conversion. The same procedure has been realized for Germylated fatty tri-alcohol and dimethyl terephtalate (Equation 2). The four branched polyesters obtained in this manner, in good yield $(90 \%$ or better) exhibit different physical properties. Products 1, 2 and $\mathbf{3}$ derived from poly(tetramethylene oxide) glycol or 1,4-butandiol are rather sticky, whereas the polyester $\mathbf{4}$ obtained from dimethyl terephtalate presents a solid aspect. These new polyesters are stable at room temperature and insensitive to moisture absorption. Consequently, they are storable and easy to handle. The equivalent linear polyester ${ }^{16}$ exhibited very satisfactory solubility in common organic solvents, whereas the new polyesters $1,2,3$ and $\mathbf{4}$ are quite insoluble in the same classic organic solvents due to their polydimensional structure. 


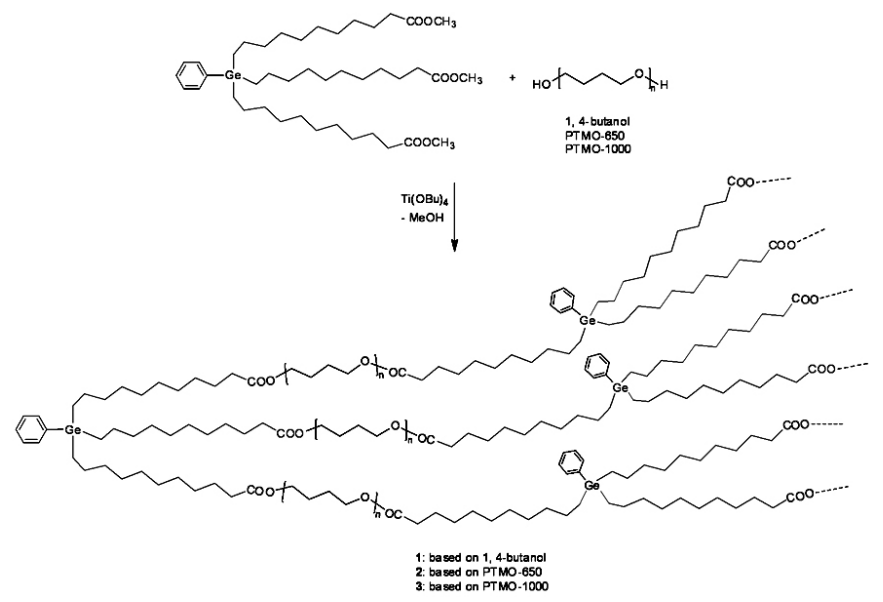

Equation 1

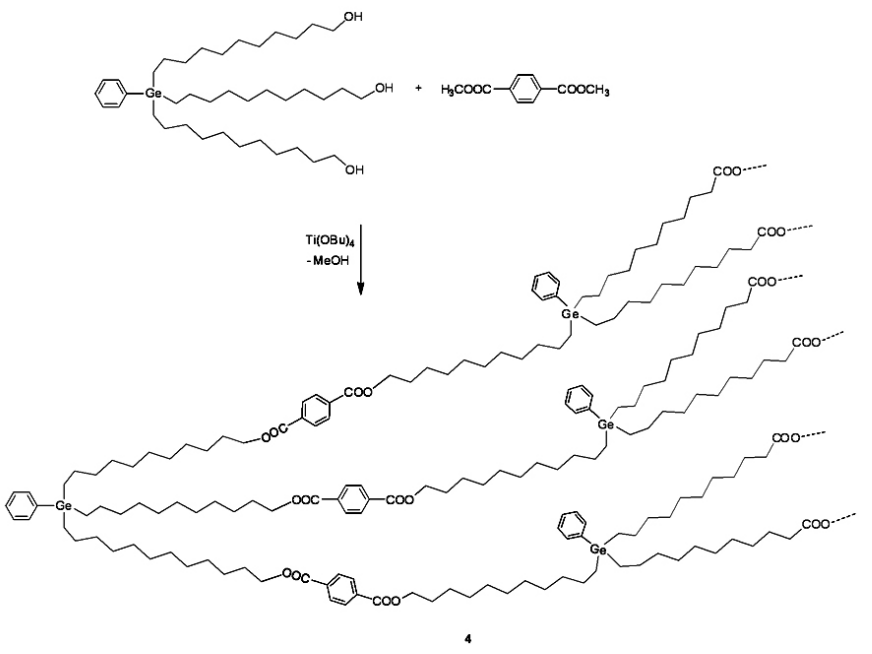

Equation 2

Elemental analyses of these products confirm the expected percent composition of Carbon and Hydrogen elements (see experimental section). IR spectra show characteristic absorptions for carbonyl $(\mathrm{C}=\mathrm{O})$ of ester functional group. A very moderate shift of carbonyl $(\mathrm{C}=\mathrm{O})$ group is observed between the monomers (Germylated fatty compounds: $1740 \mathrm{~cm}^{-1}$ ) and branched polyesters $\left.1722-1740 \mathrm{~cm}^{-1}\right)$. This is suggestive of the absence of the complexation between the oxygen of the carbonyl group and the germanium center, considering interactions between neighbor chains.

In order to obtain more information about the structure of these branched polyesters of Germanium, ${ }^{13} \mathrm{C}$ CP MAS NMR have been carried out on products 1 and 4 . The resonance due to the characteristic signals of the starting reactants, the methoxy groups of the germylated fatty tri-ester and the $\mathrm{CH}_{2} \mathrm{OH}$ group of germylated fatty tri-alcohol, were absent, indicating that the transesterification reaction was complete. For product 1, a new signal appears at $63.56 \mathrm{ppm}$ assignable to the $\mathrm{CH}$ group neighboring the ester fragment (OCO). Like the previous case of product $\mathbf{1}$, the ${ }^{13} \mathrm{C}$ CP MAS NMR spectrum of product $\mathbf{4}$ also shows a new signal at $65.29 \mathrm{ppm}$ attributed to $\mathrm{CH}_{2}$ group neighboring the ester fragment $(\mathrm{OCO})$. The chemical shifts of the carbonyl $(\mathrm{C}=\mathrm{O})$ group of the esters in the diester monomers and branched polyester are very close, confirming again the absence of interactions with the germanium centers.

The thermal behavior of the polymer samples was examined by means of TGA (Thermogravimetry analysis) as well as DSC (Differential Scanning Calorimetry). Different temperature values are used to represent the extent of the thermal decomposition in a polymer sample, e. g., Ti, is the onset decomposition and T50, is the temperature at which the weight loss reaches 50 weight $\%$. Polyesters degradation trends are shown graphically in Figure 1. Table 1 displays the TGA results relating to the temperatures corresponding to the degradation onset temperature, and the temperature for $50 \%$ weight loss.

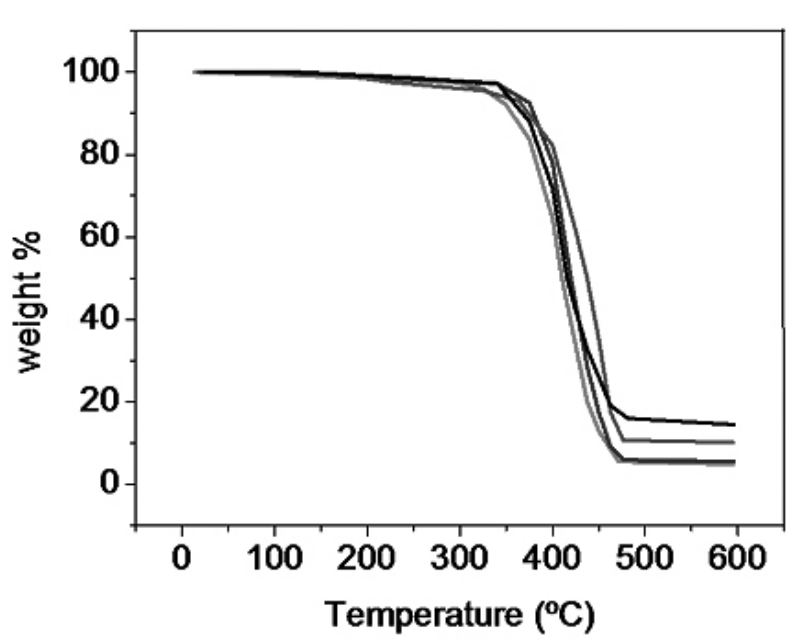

Fig. 1 Thermal decomposition profiles of polymers $1(-), 2(-), 3(-)$ and $4(-)$.

Table 1: Ti and T50 for $\mathbf{1 , 2 , 3}$ and $\mathbf{4}$ products.

\begin{tabular}{|c|c|c|}
\hline Product & $\mathrm{Ti}\left({ }^{\circ} \mathrm{C}\right)$ & $\mathrm{T} 50\left({ }^{\circ} \mathrm{C}\right)$ \\
\hline $\mathbf{1}$ & 297.8 & 410.0 \\
\hline $\mathbf{2}$ & 339.1 & 420.0 \\
\hline $\mathbf{3}$ & 363.9 & 437.5 \\
\hline $\mathbf{4}$ & 341.2 & 415.6 \\
\hline
\end{tabular}

The polymers presented relatively high thermal stability, with the onset decomposition Ti being around $300^{\circ} \mathrm{C}$ and the T50 over $400{ }^{\circ} \mathrm{C}$ for the less stable product. In all cases, a two-stage decomposition is observed. The first stage corresponds to a small weight loss (around 3 weight \%) which is most likely due to the liberation of low molecular weight volatiles species (oligomers) or remaining solvent, whereas the second stage corresponds to the greater weight loss about 80 weight percent, which is assigned to the chain scission of the polymers. It is interesting to note that the decomposition of the polymer 4 (Figure 1) resulted in the highest residual mass content, about 14 weight $\%$, imparted by the molecular structure of monomeric units involved in its formation: dimethyl terephtalate and the germylated trialcohol $\mathrm{PhGe}\left[\left(\mathrm{CH}_{2}\right)_{11} \mathrm{OH}\right]_{3}$.

It is well known that aromatic rings produce a residual free carbon at elevated temperatures much more effectively than linear hydrocarbon chains ${ }^{37}$. Also, the presence of aromatic rings in the precursors enhances processing properties.

As stated for amphiphilic polyesters derived from silylated and germylated fatty compounds previously reported ${ }^{16}$, an increase in miscibility favors polymerization and thus gives polymers of higher molecular weight. The higher molecular weight polymers give rise to higher pyrolysis residues. This behavior is consistent with that also observed for similar preceramic polymer systems, such as polysicarbosilanes and polycarbosizanes ${ }^{37}$.

The transesterification reaction of germylated fatty tri-ester to obtain $\mathbf{1 , 2}$ and $\mathbf{3}$ involved the use of three different diol monomers; 1,4-butandiol, PTMO 650 and PTMO 1000 represented by the following general structure:

$\mathrm{HO}-\left[\mathrm{CH}_{2}-\mathrm{CH}_{2}-\mathrm{CH}_{2}-\mathrm{CH}_{2}-\mathrm{O}-\right]_{n}-\mathrm{H}$

Considering that the formula weight of the repeating unit $\left[\mathrm{CH}_{2} \mathrm{CH}_{2} \mathrm{CH}_{2} \mathrm{CH}_{2} \mathrm{O}\right]$ is $\mathrm{M}_{0}=72 \mathrm{~g} / \mathrm{mol}: \mathrm{n}=1$ for 1,4-butandiol, $\mathrm{n}$ (average) $=$ 8.8 for PTMO 650 and $\mathrm{n}$ (average) $=13.6$ for PTMO 1000. Thermal stability shows an increasing trend upon increasing of diol lengths: Ti and T50 increase as $\mathrm{n}$ increases. This behavior can be interpreted in terms of a higher number of macromolecular conformations which allow dipolar interactions between different chain segments, as a consequence of the carbonyl groups and oxygen atoms of the ester groups. Thus, additional energy must be absorbed by the biopolyester to overcome such interactions before degradation.

The highly cross-linked polymers synthesized from polyfunctional monomers have different physical properties compared to their linear counterparts. Linear polymers consisting of individual chains may slide over one another when the thermal energy is sufficient. In contrast, in three- 
dimensional structures of the polymers highly cross-linked by covalent bonds, molecules no longer can move relative to one another. As a result, it is not surprising that all branched polymers are insoluble and do not melt or flow ${ }^{38}$ The experimental evidence corroborates the theoretical background since the products 1, 2, 3 and $\mathbf{4}$ could not be analyzed by NMR techniques in solution due to their insolubility in classical organic solvents. Moreover, no melting signals were observed in the corresponding thermograms obtained by DSC, as it can be observed in the thermogram of the product 1 (Figure 2), as a representative example. Figure 3 also presents the thermogram ${ }^{16}$ corresponding to the monomer PTMO-1000, which shows a clear melting signal about 20 ${ }^{\circ} \mathrm{C}$. The corresponding calorimetric ${ }^{16}$ data to PTMO-650 and PTMO-1000 are collected in Table 2.

Table 2: DSC data of PTMO monomers

\begin{tabular}{|c|c|c|c|c|}
\hline Compound & $\mathrm{T}_{\mathrm{m}}\left({ }^{\circ} \mathrm{C}\right)$ & $\Delta \mathrm{H}_{\mathrm{m}}(\mathrm{kJ} / \mathrm{mol})$ & $\mathrm{T}_{\mathrm{c}}\left({ }^{\circ} \mathrm{C}\right)$ & $\Delta \mathrm{H}_{\mathrm{c}}(\mathrm{kJ} / \mathrm{mol})$ \\
\hline PTMO-650 & 18.1 & 36.9 & -4.9 & -46.2 \\
\hline PTMO-1000 & 21.9 & 86.3 & 1.1 & -96.5 \\
\hline
\end{tabular}

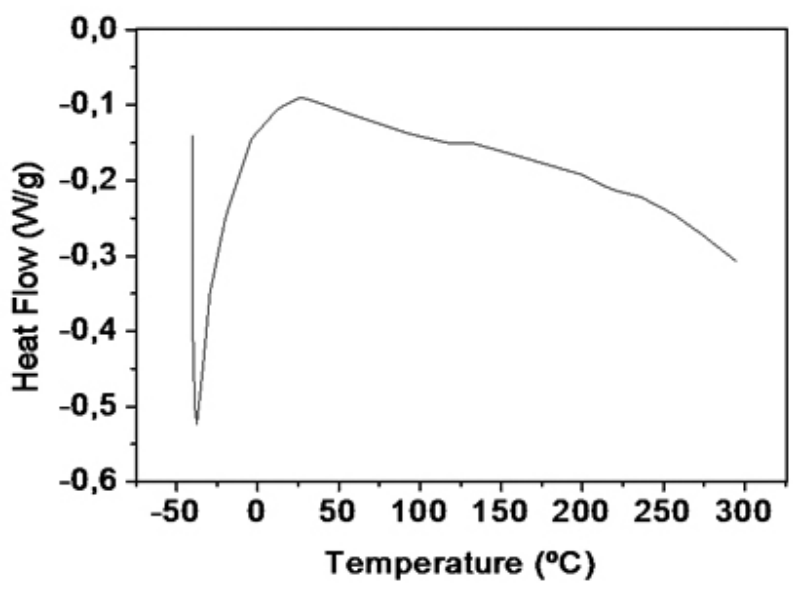

Fig. 2 Thermogram of $\mathbf{1}$

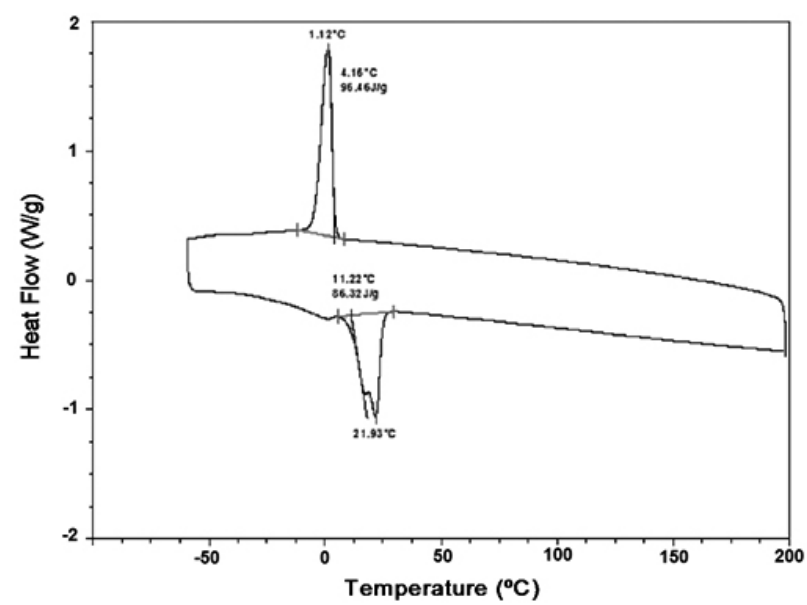

Fig. 3 Thermogram of PTMO-1000.

\section{CONCLUSION}

In conclusion, it has been shown that a new class of branched organogermylated polyesters is accessible through transesterification reactions of either fatty alcohol with esters or fatty esters with polyglycols, in rather high yields. The resulting products are characterized as insoluble in common solvents, having different properties ranging from sticky to solid, and all are amorphous polymers.
The comparison of branched polysesters and linear analogs indicates that the presence and the number of benzyl groups around a germanium atom in the monomer have a significant effect on the crystallinity and solubility of the polymer. Branched organogermylated polyesters are stable at room temperature but decompose when heated above $300^{\circ} \mathrm{C}$. Pyrolysis yield depends on polymer design and functional groups. The solid residue after pyrolysis under inert atmosphere increases with the aromatic content of the original monomers. The phenyl-germanium bond appears to be particularly attractive choice on which to base branched-polyesters. Additional analyses of these materials are still in progress, in order to study the macromolecular organization and potential applications in nanoscience.

\section{EXPERIMENTAL}

\subsection{Materials}

All reactions were performed under nitrogen using standard Schlenk tube techniques, and dry solvents. Poly(tetramethylene oxide) glycol with a molecular weight $\mathrm{M}_{\mathrm{n}}$ of 650 and $1000 \mathrm{~g} / \mathrm{mol}, 1,4-$ butandiol, dimethyl terephtalate and titanium-tetrabutoxide $\mathrm{Ti}(\mathrm{OBu})_{4}$ were purchased from Aldrich and used as received. Germylated fatty tri-ester and tri-alcohol were prepared according to the literature procedure ${ }^{17-18}$. Titanium-tetrabutoxide $\mathrm{Ti}(\mathrm{OBu})_{4}$ was used in a $1 \%$ concentration relative to organic reagents.

\subsection{Characterization Techniques}

Several analytical techniques have been used to characterize the polymers. ${ }^{13} \mathrm{C}$ CP MAS NMR spectra were recorded at the resonance frequency of 100.49 $\mathrm{MHz}$ on a Bruker Avance 400 WB. FTIR studies were conducted with a Perkin Elmer 1600 FT spectrometer. C, H elemental analyses have been carried out with a Perking Elmer PE 2400 elemental analyzer.

Thermogravimetric (TG) measurements were conducted with a STA 625 system in platinum pans at a fixed heating rate of $10^{\circ} \mathrm{C} / \mathrm{min}$ in a range of $25^{\circ} \mathrm{C}$ to $550^{\circ} \mathrm{C}$ under nitrogen atmosphere $(42 \mathrm{~mL} / \mathrm{min})$. Differential scanning calorimetry (DSC) was performed with a TA Q200 Instrument in sealed aluminium pan under nitrogen atmosphere (gas flow: $50 \mathrm{~mL} / \mathrm{min}$ ) in the temperature range from -60 to $200^{\circ} \mathrm{C}$ at a heating and cooling rate of $5^{\circ} \mathrm{C} / \mathrm{min}$. The polymers were heated from to $-60^{\circ} \mathrm{C}$ to $200^{\circ} \mathrm{C}$ (First scan), cooled to $-60^{\circ} \mathrm{C}$ (second scan) and then heated again to $200^{\circ} \mathrm{C}$ (third scan).

\subsection{Synthesis}

4.3.1 Preparation of branched polymer 1:

1,4-butandiol $(0.09 \mathrm{~g}, 1.00 \mathrm{mmol})$ and $\mathrm{Ti}(\mathrm{OBu})_{4}$ were added to Germylated tri-ester $\mathrm{PhGe}\left[\left(\mathrm{CH}_{2}\right)_{10}-\mathrm{COOCH}_{3}\right]_{3}(0.50 \mathrm{~g}, 0.67 \mathrm{mmol})$ with stirring. The mixture was heated to $140^{\circ} \mathrm{C}$ and the pressure was reduced to $0.5 \mathrm{mmHg}$. When the temperature reached $190^{\circ} \mathrm{C}$, the polycondensation in the melt was stirred for $1 \mathrm{~h}$. After cooling at room temperature, the mixture was washed with $10 \mathrm{~mL}$ of hexane and filtered. $0.49 \mathrm{~g}$ of a sticky product, referenced by 1 , was obtained. Yield: $70 \%$.

IR: $v(\mathrm{C}=\mathrm{O})=1737 \mathrm{~cm}^{-1}$. RMN ${ }^{13} \mathrm{C}$ (solid state) $(100.49 \mathrm{MHz}): \delta(\mathrm{ppm})=$ $13.22\left(\mathrm{CH}_{2}-\mathrm{Ge}\right) ; 25.25-34.12\left(\mathrm{CH}_{2}\right.$ alkyl chains $) ; 63.56\left(\mathrm{COOCH}_{2}\right) ; 128.09-$ 140.27 (aromatic carbon); 172.49 (CO). Elemental analysis: Anal. Calcd for $\mathrm{C}_{90} \mathrm{H}_{154} \mathrm{O}_{12} \mathrm{Ge}_{2}: \mathrm{C}, 68.74 ; \mathrm{H}, 9.80$. Found: $\mathrm{C}, 69.11 ; \mathrm{H}, 10.05$.

4.3.2 Preparation of branched polymer 2 :

A similar procedure to that described for $\mathbf{1}$ was used. Germylated tri-ester $(0.50 \mathrm{~g}, 0.67 \mathrm{mmol})$, poly(tetramethylene oxide) glycol with $\mathrm{M}_{\mathrm{n}}$ of $650 \mathrm{~g} / \mathrm{mol}$ (PTMO-650) $(0.65 \mathrm{~g}, 1.00 \mathrm{mmol})$ and $\mathrm{Ti}(\mathrm{OBu})_{4}$ gave $2: 1.00 \mathrm{~g}$ as a sticky solid. Yield: $90 \%$.

IR: $v(\mathrm{C}=\mathrm{O})=1738 \mathrm{~cm}^{-1}$. Elemental analysis: Anal. Calcd for $\mathrm{C}_{186} \mathrm{H}_{346} \mathrm{O}_{36} \mathrm{Ge}_{2}: \mathrm{C}, 67.65 ; \mathrm{H}, 10.49$. Found: $\mathrm{C}, 67.92 ; \mathrm{H}, 10.63$.

4.3.3 Preparation of branched polymer 3 :

A similar procedure to that described for $\mathbf{1}$ was used. Germylated tri-ester $(0.50 \mathrm{~g}, 0.67 \mathrm{mmol})$, poly(tetramethylene oxide) glycol with $\mathrm{M}_{\mathrm{n}}$ of $1000 \mathrm{~g} / \mathrm{mol}$ (PTMO-1000) $(1.00 \mathrm{~g}, 1.00 \mathrm{mmol})$ and $\mathrm{Ti}(\mathrm{OBu})_{4}$ gave 3: $1.00 \mathrm{~g}$ as a sticky solid. Yield: $92 \%$.

IR: $v(\mathrm{C}=\mathrm{O})=1740 \mathrm{~cm}^{-1}$. Elemental analysis: Anal. Calcd for $\mathrm{C}_{246} \mathrm{H}_{466} \mathrm{O}_{51} \mathrm{Ge}_{2}: \mathrm{C}, 67.41 ; \mathrm{H}, 10.64$. Found. C, 67.75; H, 10.83 .

4.3.4 Preparation of branched polymer 4 :

Dimethyl terephtalate $(0.22 \mathrm{~g}, 1.13 \mathrm{mmol})$ and $\mathrm{Ti}(\mathrm{OBu})_{4}$ were added to Germylated tri-alcohol $\mathrm{PhGe}\left[\left(\mathrm{CH}_{2}\right)_{11}-\mathrm{OH}\right]_{3}(0.50 \mathrm{~g}, 0.75 \mathrm{mmol})$ with stirring. The mixture was heated to $170^{\circ} \mathrm{C}$ and the pressure was reduced to $0.5 \mathrm{mmHg}$. When the temperature reached $190^{\circ} \mathrm{C}$, the polycondensation in the melt was stirred for $1 \mathrm{~h}$. After cooling at room temperature, the mixture was washed with $10 \mathrm{~mL}$ of hexane and filtered. $0.67 \mathrm{~g}$ of a white solid referenced by 4 , was obtained. Yield: $98 \%$.

IR: $v(\mathrm{C}=\mathrm{O})=1722 \mathrm{~cm}-1 . \mathrm{RMN}{ }^{13} \mathrm{C}$ (solid state) $(100.49 \mathrm{MHz}): \delta(\mathrm{ppm})$ $=13.16\left(\mathrm{CH}_{2}-\mathrm{Ge}\right) ; 26.25-33.48\left(\mathrm{CH}_{2}\right.$ alkyl chains $) ; 65.29\left(\mathrm{COOCH}_{2}\right) ; 128.24-$ 
140.18 (aromatic carbon); 164.82(CO). Elemental analysis: Anal. Calcd for $\mathrm{C}_{102} \mathrm{H}_{154} \mathrm{O}_{6} \mathrm{Ge}_{2}: \mathrm{C}, 75.59 ; \mathrm{H}, 9.51$. Found: $\mathrm{C}, 75.94 ; \mathrm{H}, 9.81$.

\section{REFERENCES}

1 U. Biermann, U. Bornscheuer, M. A. R. Meier, J.O. Metzger, H. J. Schafer, Angew. Chem. Int. Ed. 50, 3854 (2011)

2 J. O. Metzger, A. Huttermann, Naturwissenschaften 96, 279 (2009)

3 A. Gandini, Macromolecules 41, 9491 (2008)

4 M. Namkajorn, A. Petchsuk, M. Opaprakasit, P. Opaprakasit, Express Polymer Letters 4, 415 (2010)

5 B. Cakmakli, B. Hazer, I. O. Tekin, F. B. Cömert, Biomacromolecules 6, $1750(2005)$

6 J. Hong, Q. Luo, X. Wan, Z.S. Petrovic, B.K. Shah, Biomacromolecules 13, $261(2012)$

7 J.C. Ronda, G. Lligadas, M. Galia, V. Cadiz, Eur J. Lipid. Sci. Tech. 113, $46(2011)$

8 B.K. Ahn, S. Kraft, D. Wang, X.S. Sun, Biomacromolecules 12, 1839 (2011)

9 Y. Lu, R.C. Larock, ChemSusChem 2, 136 (2009)

10 X. Kong, J. Yue, S.S. Narine, Biomacromolecules 8, 3584 (2007)

11 U. Biermann, W. Friedt, S. Lang, W. Luhs, G. Machmuller, J.O. Metzger, M.R. Klaas, H.J. Schafer, M.P. Schneider, Ang. Chem. Int. Ed. 39, 2206 (2000)

12 S.S. Narine, X. Kong, L. Bouzidi, P. Sporns, J. Am. Oil Chem. Soc. 84, 55 (2007)

13 V. Sharma, P.P.Kundu, Prog. Polym. Sci. 31, 983 (2006)

14 M.A. Tehfe, J. Lalevee, D. Gigmes, J.P. Fouassier, Macromolecules 43, $1364(2010)$

15 I. Javni, D.P. Hong, Z.S. Petrovic, J. Appl. Polym. Sci. 108, 3867 (2008)

16 N. Katir, A. El Kadib, M. Dahrouch, A. Castel, N. Gatica, Z. Benmaarouf, P. Riviere, Biomacromolecules 10, 850 (2009).

17 N. Katir, A. El Kadib, A. Castel, P. Riviére, Z. Benmaarouf, Appl. Organomet. Chem. 22, 402 (2008)

18 N. Katir, A. El Kadib, A. Castel, P. Riviére, M. Bousmina, Z. Benmaarouf, Curr. Org. Chem. 15, 3544 (2011)

19 G.J. Zhou, W.Y. Wong, Chem. Soc. Rev. 40, 2541 (2011)

20 C. Qin, W.Y. Wong, L. Wang, Macromolecules 44, 483 (2011)

21 A.Presa-Soto, I. Manners, Macromolecules 42, 40 (2009)

22 L. Liu, D. Fortin, P.D. Harvey, Nanometer Length-Dependent TripletTriplet Energy Transfers in Zinc(II)Porphyrin/trans-Bis(ethynylbenzene) Platinum(II) Oligomers, Inorg. Chem. 48, 5891 (2009)

23 I. Manners, in Comprehensive Organometallic Chemistry III, ed. By M. Mingos ,R. H. Crabtree (Elsevier, Amsterdam, 2007), p. 295

24 W.Y. Wong, Coordin. Chem. Rev. 251, 2400 (2007).

25 M. Dahrouch, M. Rivière-Baudet, N. Katir, J. Alvarez, E. Diaz., P. Rivière, A. Castel, I. Chavez, J. M. Manriquez, Inorg. Chim. Acta 360, 4031 (2007)

26 S. Boughdiri, K. Hussein, B. Tangour, M. Dahrouch, M. Rivière-Baudet, J.C. Barthelat, J. Organomet. Chem. 689, 3279 (2004)

27 M. Rivière-Baudet, M. Dahrouch, H. Gornitzka, Phosphorus, Sulfur, and Silicon and the Related Elements 159, 23 (2000)

28 M. Dahrouch, M. Rivière-Baudet, J. Satgé, M. Mauzac, C.J. Cardin, J.H. Thorpe, Organometallics 17, 623 (1998)

29 H. Frey, Highly Branched Polymers, Macromol. Chem. Phys. 208, 1613 (2007)

30 A. Carlmark, C. Hawker, A. Hult, M. Malkoch, Chem. Soc. Rev. 38, 352 (2009)

31 D. Yan, C. Gao, H. Frey, Hyperbranched Polymers: Synthesis, Properties and Applications, third edn. (Wiley, New York, 2009)

32 B. Voit, A. Lederer, Chem. Soc. Rev. 109, 5924 (2009)

33 C. E. Carraher Jr., A. Morrison, M. R. Roner, A. Moric, N. T. Trang, J. Inorg. Organomet. Polym. 24, 182 (2014)

34 J. Brassinne, C. A. Fustin, J. F. Gohy, J. Inorg. Organomet. Polym. 23, 24 (2013)

35 A. Hult, M. Johansson, E. Malmstroem, Hyperbranched Polymers, Adv. Polym. Sci.143, 1 (1999)

36 J.F. Stumbe, B. Bruchmann, Macromol. Rapid Comm. 25, 921 (2004)

37 D. Bahloul-hourlier, J. Latournerie, P. Dempsey, J. Eur. Ceram. Soc. 25, 979 (2005)

38 A. Hort, Macromoléculas, (Universidad Nacional de Educación a Distancia, Madrid, 1991)

\section{ACKNOWLEDGMENTS}

The authors thank the projects FONDECYT 1130606, DIUC 209.023.0451.0 and DIUC 212.023.049-1.0, the "Vicerrectoría de Investigación y Facultad de Ciencias Químicas de la UNIVERSIDAD DE CONCEPCION" for partial financial support. 